\title{
Perspectivas do uso da psicodinâmica do trabalho no Brasil: teoria, pesquisa e ação
}

\author{
Álvaro Roberto Crespo Merlo e Ana Magnólia Bezerra Mendes ${ }^{\mathrm{II}}$ \\ ${ }^{\text {I }}$ Programa de Pós-Graduação em Psicologia Social, \\ Instituto de Psicologia da Universidade Federal do Rio Grande do Sul \\ II Programa de Pós-Graduação em Psicologia Social e do Trabalho e das Organizações, \\ Instituto de Psicologia da Universidade de Brasília
}

\begin{abstract}
Este artigo tem a intenção de refletir sobre o uso da psicodinâmica do trabalho no Brasil como teoria e método, e como tal, o papel que vem desempenhando para a compreensão das relações entre a saúde mental e o trabalho. Trata-se de uma abordagem preliminar e exploratória, que teve como base 79 artigos, dissertações, teses e outras publicações que apontam o modo como a psicodinâmica do trabalho vem sendo referenciada. Observa-se que, na grande maioria das vezes, a psicodinâmica é usada apenas como referencial teórico, sem terem sido seguidos os passos propostos no método para a investigação. Considera-se que, apesar de suas categorias teóricas serem amplamente utilizadas por pesquisadores brasileiros, ainda há um grande desconhecimento da potencialidade que oferece esse instrumento, enquanto método e possível prática, para o avanço do conhecimento neste campo de pesquisa e sua aplicação.
\end{abstract}

Palavras-chave: Sofrimento psíquico, Processo de trabalho, Saúde mental, Método.

Perspectives of psychodynamics of work use in Brazil: theory, method, and practice

This article has the intention of contemplating about the use of the methodology of psychodynamics of work in Brazil as theory, method and practice, while a score for the understanding of the relationships between the mental health. It is treated of an exploratory approach that had as base 79 articles, dissertations, thesis, etc. where the methodology of psychodynamics of Work was used as a reference. It was observed that that methodology was used, in the great majority of the times, just as a theoretical reference, without it being following the steps proposed in the method for the investigation. It is considered that, in spite of their categories they be used thoroughly by Brazilian researchers, there is still a great ignorance of the potentiality that offers that instrument.

Keywords: Mental suffering, Worker process, Mental health, Method.

\section{Introdução}

$\mathrm{N}$

ossa proposta neste texto foi a de refletir sobre o uso da psicodinâmica do trabalho no Brasil. Trata-se de uma abordagem exploratória. Ela teve como base o período de 1996 a 2009, no qual foram encontrados 79 artigos disponíveis nas bases de dados Scielo Brasil (Scientific Electronic Library Online) e PePSIC (Periódicos Eletrônicos em Psicologia), além de dissertações e teses disponíveis para consulta via internet e outros textos publicados em livros nos quais a psicodinâmica do trabalho foi utilizada como uma referência. Nossa intenção foi apresentar uma primeira revisão do que tem sido publicado no Brasil sobre o assunto, mas com o objetivo de construir uma reflexão - preliminar e exploratória - sobre o uso da psicodinâmica do trabalho enquanto abordagem teóricometodológica de pesquisa e ação, visando ampliar e fortalecer a pesquisa e as ações no campo da saúde mental e trabalho.

O percurso da produção brasileira em psicodinâmica do trabalho teve início na década de 1980 e acompanha o desenvolvimento da própria teoria, preconizada por Christophe 
Dejours, estando envolvidas nessa rede de construção, todas as tensões necessárias para o avanço científico de uma teoria e de sua aplicação.

O lançamento no Brasil do livro A loucura do trabalho, de Christophe Dejours, em 1987, com o novo aporte teórico trazido pela obra, tornou-se referência para quase todos os pesquisadores que atuam na área. A discussão e a abordagem apresentadas nesse livro eram novas, trouxeram muitas respostas e abriram caminhos para que se pudesse pensar as consequências do trabalho - em especial pela forma como ele trabalho está organizado sobre a saúde psíquica dos trabalhadores. A nova proposta veio preencher uma lacuna na maneira como eram compreendidas essas relações, que, até aquele momento, encontravamse restritas a enfoques da psiquiatria e da psicologia do trabalho, para os quais o trabalho representava, quando muito, um "fator desencadeante" de distúrbios latentes. A nova abordagem mesclava categorias da psicologia, da psicanálise, da ergonomia e da sociologia do trabalho para poder pensar o papel que o trabalho jogava na construção do (difícil) equilíbrio psíquico que os trabalhadores devem estabelecer para se manterem saudáveis em ambientes de trabalho muito hostis.

A incorporação de conceitos da sociologia do trabalho foi fundamental, como, por exemplo, os referentes aos modelos de gestão e de organização dos processos de trabalho nos quais estão inseridos os trabalhadores e que têm produzido graves consequências sobre a saúde mental. Estas têm origem, historicamente, nas diversas transformações ocorridas nos mundos do trabalho, tal como a introdução do parcelamento das tarefas no período da manufatura, ainda no século XIX, na separação entre concepção e execução, introduzida pelos modelos taylorista e fordista e, mais recentemente, nas mudanças promovidas pela implementação dos modelos ditos "flexíveis", que passaram a demandar um trabalhador mais engajado em seu trabalho, apto a realizar diversas operações e muito mais submetido aos processos produtivos. Ao sofrimento daqueles que trabalhavam em tarefas que ainda não foram atingidas pela reestruturação produtiva, acrescentou-se o sofrimento provocado pelas transformações em curso no trabalho, atingindo a saúde física e mental. Nas realidades de trabalho brasileiras encontramos, muitas vezes, uma combinação de modelos de gestão "antigos" (tayloristafordista) com a implementação simultânea de instrumentos dos modelos da reestruturação flexível, dentro de ambientes de trabalho que não superaram a insalubridade e a periculosidade, gerados durante a formação do parque industrial brasileiro no século passado. Essa combinação produziu um modelo próprio dos países da periferia capitalista, que poderíamos apelidar de "modelo frankenstein", pois reúne, em um mesmo ambiente de trabalho, agressões à saúde física e psíquica de vários modelos, produzindo um resultado negativo potencializado (Merlo \& Lapis, 2007).

É importante lembrar, ainda, os aspectos relacionados à (re)estruturação do mundo do trabalho e à divisão internacional da economia que tem, ainda que indiretamente, repercussões sobre a saúde psíquica (e física) dos trabalhadores, na medida em que contribuem para definir as formas diferentes de como o trabalho deve ser exercido em um determinado país. Configurou-se uma divisão internacional das formas de trabalhar, na qual exportaram-se, preferencialmente para a periferia, atividades produtivas muito exigentes de mão-de-obra, tal como o que ocorre atualmente na produção de vestuários ou de calçados, a qual funciona em moldes tayloristas e fordistas criados há quase 100 anos.

Para Dejours (1987b), o campo da psicodinâmica do trabalho é aquele do sofrimento e do conteúdo, da significação e das formas desse sofrimento. Ele situa sua investigação no contexto do infra-patológico ou do pré-patológico. Para o autor, o sofrimento é um espaço clínico intermediário, que marca a evolução de uma luta entre, por um lado, funcionamento psíquico e mecanismo de defesa e, de outro, pressões organizacionais desestabilizantes, com o objetivo de conjurar a descompensação e conservar, apesar de tudo, um equilíbrio possível, mesmo se ele ocorrer ao preço de um sofrimento, com a condição que se preserve o conformismo aparente do comportamento e satisfaçam-se os critérios sociais de normalidade. 
Esse conceito foi, posteriormente, revisado a partir de um privilegiamento do estudo da normalidade sobre o da patologia, pois o que importa para a psicodinâmica do trabalho é conseguir compreender como os trabalhadores alcançam manter um certo equilíbrio psíquico, mesmo estando submetidos a condições de trabalho desestruturantes (Dejours, 2004).

Outra característica importante é que a psicodinâmica do trabalho visa ao coletivo de trabalho e não aos indivíduos isoladamente. Após diagnosticar o sofrimento psíquico em situações de trabalho, ela não busca atos terapêuticos individuais, mas intervenções voltadas para a análise da organização do trabalho à qual os indivíduos estejam submetidos. Especialmente para as estratégias construídas coletivamente para dar conta do trabalho prescrito, evitando o sofrimento e buscando o prazer.

Pensamos que o principal mérito da psicodinâmica do trabalho foi o de ter exposto as possibilidades de agressão mental originadas na organização do trabalho e identificáveis ainda em uma etapa pré-patológica, pois, na medida em que não é possível falar-se de distúrbios que possam ser associados a uma situação específica de trabalho, o desvendamento do sofrimento psíquico desde o estado pré-patológico permite progredir na identificação das consequências das organizações do trabalho sobre a saúde mental dos indivíduos e pensar em uma intervenção preventiva. Em várias atividades nas quais não se encontram, praticamente, agressões imediatamente observáveis - diferentemente dos acidentes de trabalho ou das intoxicações -, os instrumentos de investigação empregados pela psicodinâmica do trabalho revelaram-se preciosos auxiliares para compreender-se a relação trabalho-doença (Merlo, 2002). A abordagem adotada por essa disciplina permitiu ultrapassar uma visão reducionista que responsabilizava apenas o individuo pelas consequências do trabalho sobre sua saúde e buscar vivências operárias específicas, que se inscrevem em realidades concretas de trabalho, como, por exemplo, o papel da inteligência operária e sua função como mecanismo de defesa e na construção de identidade no trabalho (Dejours, 1992).

Nesse sentido, a saúde mental para a psicodinâmica coloca-se entre a patologia e a normalidade, ou seja, resulta dos modos como os sujeitos-trabalhadores reagem e agem frente ao sofrimento originado nos constrangimentos impostos pela organização do trabalho. $O$ sofrimento é o modo de evitar a patologia. O trabalhador, ao mesmo tempo, sofre e busca não sofrer com a experiência de fracasso decorrente da falibilidade humana frente ao trabalho real. O sujeito entra em contato com a imperfeição e a falta, elementos indissociáveis do fazer, dada a condição permanente do trabalho, que será sempre inacabado.

\section{O uso da psicodinâmica do trabalho em pesquisa no Brasil}

No quadro a seguir, encontramos a lista dos artigos, dissertações e teses acessados que tiveram a psicodinâmica do trabalho como referência.

Quadro 1: Artigos, dissertações e teses que referenciaram o uso da psicodinâmica do trabalho

\begin{tabular}{|l|c|c|c|}
\hline \multicolumn{1}{|c|}{ Título } & Ano & Periódico/origem & Uso \\
\hline $\begin{array}{l}\text { A Influência da organização do trabalho nas vivências de } \\
\text { prazer-sofrimento dos trabalhadores: uma abordagem } \\
\text { psicodinâmica }\end{array}$ & 1996 & Psicologia Teoria e Pesquisa & $\begin{array}{l}\text { categoria teórico- } \\
\text { metodológica }\end{array}$ \\
\hline Temporalidade e subjetividade no trabalho informatizado & 1996 & Doutorado em Psicologia & categoria teórica \\
\hline $\begin{array}{l}\text { Saúde mental e automação: a propósito de um estudo de caso } \\
\text { no setor ferroviário }\end{array}$ & 1997 & Cadernos de Saúde Pública & categoria teórica \\
\hline
\end{tabular}




\begin{tabular}{|c|c|c|c|}
\hline $\begin{array}{l}\text { A construção do campo da saúde do trabalhador: percurso e } \\
\text { dilemas }\end{array}$ & 1997 & Cadernos de Saúde Pública & categoria teórica \\
\hline $\begin{array}{l}\text { Relações de trabalho e inovação tecnológica na gerência de } \\
\text { sistemas de uma organização produtora de jornais }\end{array}$ & 1999 & $\begin{array}{l}\text { Revista de Administração } \\
\text { Contemporânea }\end{array}$ & categoria teórica \\
\hline $\begin{array}{l}\text { As condições e a organização de trabalho dos policiais } \\
\text { militares que executam o policiamento ostensivo: um estudo } \\
\text { de caso na Brigada Militar em Porto Alegre/RS }\end{array}$ & 1999 & Mestrado em Administração & categoria teórica \\
\hline Alunos problemas - professores despreparados & 2000 & $\begin{array}{l}\text { Mestrado em Engenharia } \\
\text { de Produção (Ergonomia) }\end{array}$ & categoria teórica \\
\hline Qualidade de vida dos profissionais de enfermagem & 2000 & Revista Espaço para a Saúde & categoria teórica \\
\hline A construção do "sujeito-doente" em LER & 2000 & $\begin{array}{l}\text { História, Ciência, Saúde - } \\
\text { Manguinhos }\end{array}$ & categoria teórica \\
\hline $\begin{array}{l}\text { A ergonomia e suas contribuições para o processo de ensino- } \\
\text { aprendizagem: uma análise das salas de aula do CEFET/RN }\end{array}$ & 2000 & $\begin{array}{l}\text { Mestrado em Engenharia } \\
\text { de Produção (Ergonomia) }\end{array}$ & categoria teórica \\
\hline $\begin{array}{l}\text { A saúde sob custódia: um estudo sobre agentes de segurança } \\
\text { penitenciária no Rio de Janeiro }\end{array}$ & 2000 & Mestrado em Saúde Pública & categoria teórica \\
\hline $\begin{array}{l}\text { Homens de pedra? Pesquisando o processo de trabalho e } \\
\text { saúde na extração e no beneficiamento do mármore - relato } \\
\text { de uma experiência }\end{array}$ & 2001 & $\begin{array}{l}\text { Cadernos de Psicologia Social } \\
\text { do Trabalho }\end{array}$ & categoria teórica \\
\hline $\begin{array}{l}\text { Aprendendo com o câncer de mama: percepções e emoções } \\
\text { de pacientes e profissionais de fisioterapia }\end{array}$ & 2001 & $\begin{array}{l}\text { Mestrado em Engenharia } \\
\text { de Produção (Ergonomia) }\end{array}$ & categoria teórica \\
\hline $\begin{array}{l}\text { Saúde mental e trabalho: uma reflexão sobre o nexo com o } \\
\text { trabalho e o diagnóstico, com base na prática }\end{array}$ & 2001 & Cadernos de Saúde Pública & categoria teórica \\
\hline $\begin{array}{l}\text { "Só de pensar em vir trabalhar, já fico de mau humor": } \\
\text { atividade de atendimento ao público e prazer-sofrimento no } \\
\text { trabalho }\end{array}$ & 2001 & Estudos de Psicologia (Natal) & categoria teórica \\
\hline $\begin{array}{l}\text { Comportamento humano no trabalho: educação profissional, } \\
\text { subjetividade e falhas operacionais na indústria }\end{array}$ & 2001 & $\begin{array}{l}\text { Revista da FAEEBA - } \\
\text { Educação e } \\
\text { Contemporaneidade }\end{array}$ & categoria teórica \\
\hline $\begin{array}{l}\text { Modelo de avaliação de projetos enfoque cognitivo e } \\
\text { ergonômico }\end{array}$ & 2001 & $\begin{array}{c}\text { Doutorado em Engenharia de } \\
\text { Produção (Ergonomia) }\end{array}$ & categoria teórica \\
\hline Valores organizacionais e prazer-sofrimento no trabalho & 2001 & Psico-USF & categoria teórica \\
\hline $\begin{array}{l}\text { Trabalho de grupo com portadores de LER/DORT: relato de } \\
\text { experiência }\end{array}$ & 2001 & Psicologia Reflexão e Crítica & categoria teórica \\
\hline $\begin{array}{l}\text { Processo de trabalho e riscos para a saúde dos trabalhadores } \\
\text { em uma indústria de cimento }\end{array}$ & 2002 & Cadernos de Saúde Pública & categoria teórica \\
\hline $\begin{array}{l}\text { O abandono do magistério: vínculos e rupturas com trabalho } \\
\text { docente }\end{array}$ & 2002 & Psicologia USP & categoria teórica \\
\hline $\begin{array}{l}\text { Sofrimento psíquico e trabalho de profissionais de } \\
\text { enfermagem }\end{array}$ & 2002 & Estudos de Psicologia (Natal) & categoria teórica \\
\hline $\begin{array}{l}\text { Prevenção de agravos à saúde do trabalhador: replanejando o } \\
\text { trabalho através das negociações cotidianas }\end{array}$ & 2002 & Cadernos de Saúde Pública & categoria teórica \\
\hline $\begin{array}{l}\text { A passagem de plantão no contexto do processo de trabalho } \\
\text { da enfermagem }\end{array}$ & 2002 & Mestrado em Enfermagem & categoria teórica \\
\hline $\begin{array}{l}\text { Cargas de trabalho encontrada nos coletores de lixo } \\
\text { domiciliar - um estudo de caso }\end{array}$ & 2002 & $\begin{array}{l}\text { Mestrado em Engenharia } \\
\text { de Produção (Ergonomia) }\end{array}$ & categoria teórica \\
\hline $\begin{array}{l}\text { Algumas contribuições teóricas do referencial psicanalítico } \\
\text { para as pesquisas sobre organizações }\end{array}$ & 2002 & Estudos de Psicologia (Natal) & categoria teórica \\
\hline $\begin{array}{l}\text { A implantação da tecnologia TPM em um equipamento na } \\
\text { Adria Alimentos do Brasil Ltda. }\end{array}$ & 2002 & $\begin{array}{c}\text { Mestrado Profissionalizante em } \\
\text { Engenharia de Produção }\end{array}$ & categoria teórica \\
\hline A "dinâmica de grupos" de Bion e as organizações de trabalho & 2002 & Psicologia USP & categoria teórica \\
\hline $\begin{array}{l}\text { Trabalho e sofrimento psíquico de caixas de agências } \\
\text { bancárias na cidade do Rio de Janeiro }\end{array}$ & 2002 & Cadernos de Saúde Pública & categoria teórica \\
\hline $\begin{array}{l}\text { Reestruturação produtiva no setor bancário brasileiro e } \\
\text { sofrimento dos caixas executivos: um estudo de caso }\end{array}$ & 2002 & Psicologia \& Sociedade & categoria teórica \\
\hline $\begin{array}{l}\text { Prazer e sofrimento no trabalho: representações sociais de } \\
\text { profissionais de recursos humanos }\end{array}$ & 2002 & Psicologia Ciência e Profissão & categoria teórica \\
\hline
\end{tabular}




\begin{tabular}{|c|c|c|c|}
\hline $\begin{array}{l}\text { Burnout em fisioterapeutas: influência sobre a atividade de } \\
\text { trabalho e bem-estar físico e psicológico }\end{array}$ & 2003 & $\begin{array}{l}\text { Mestrado em Engenharia } \\
\text { de Produção (Ergonomia) }\end{array}$ & categoria teórica \\
\hline $\begin{array}{l}\text { Avaliação do sistema de gestão de riscos de acidentes com } \\
\text { instrumentos pérfuro-cortantes na atividade de limpeza de } \\
\text { hospitais públicos através da análise ergonômica do trabalho }\end{array}$ & 2003 & $\begin{array}{l}\text { Mestrado em Engenharia } \\
\text { de Produção (Ergonomia) }\end{array}$ & categoria teórica \\
\hline $\begin{array}{l}\text { Sofrimento psíquico no trabalho e estratégias defensivas dos } \\
\text { operários terceirizados da construção civil }\end{array}$ & 2003 & Psico-USF & categoria teórica \\
\hline $\begin{array}{l}\text { Abordagens teórico-metodológicas em saúde/doença mental } \\
\text { \& trabalho }\end{array}$ & 2003 & Psicologia \& Sociedade & categoria teórica \\
\hline Saúde mental e psicologia do trabalho & 2003 & São Paulo em Perspectiva & categoria teórica \\
\hline $\begin{array}{l}\text { Incorporação das ciências sociais na produção de } \\
\text { conhecimentos sobre trabalho e saúde }\end{array}$ & 2003 & Ciência \& Saúde Coletiva & categoria teórica \\
\hline $\begin{array}{l}\text { O desenvolvimento compartilhado de impressos como } \\
\text { estratégia de educação em saúde junto a trabalhadores de } \\
\text { escolas da rede pública do Estado do Rio de Janeiro }\end{array}$ & 2003 & Cadernos de Saúde Pública & categoria teórica \\
\hline Trabalho e saúde na indústria têxtil de amianto & 2003 & São Paulo em Perspectiva & categoria teórica \\
\hline $\begin{array}{l}\text { O trabalho entre prazer, sofrimento e adoecimento: a } \\
\text { realidade dos portadores de lesões por esforços repetitivos }\end{array}$ & 2003 & Psicologia \& Sociedade & categoria teórica \\
\hline $\begin{array}{l}\text { Trabalho e subjetividade: o olhar da psicodinâmica do } \\
\text { trabalho }\end{array}$ & 2003 & $\begin{array}{c}\text { Cadernos de Psicologia Social } \\
\text { do Trabalho }\end{array}$ & categoria teórica \\
\hline $\begin{array}{l}\text { Entre a organização do trabalho e o sofrimento: o papel de } \\
\text { mediação da atividade }\end{array}$ & 2004 & Revista Produção & categoria teórica \\
\hline $\begin{array}{l}\text { A transformação do sofrimento em adoecimento: do } \\
\text { nascimento da clínica à psicodinâmica do trabalho }\end{array}$ & 2004 & Ciência \& Saúde Coletiva & categoria teórica \\
\hline $\begin{array}{l}\text { Ser auxiliar de enfermagem: um olhar da psicodinâmica do } \\
\text { trabalho }\end{array}$ & 2004 & Revista Produção & categoria teórica \\
\hline $\begin{array}{l}\text { Gestão do conhecimento como processo de } \\
\text { institucionalização da mais-valia relativa }\end{array}$ & 2004 & $\begin{array}{l}\text { Anais do XXIV Encontro } \\
\text { Nacional de Engenharia de } \\
\text { Produção }\end{array}$ & categoria teórica \\
\hline $\begin{array}{l}\text { Psicologia do trabalho e psicologia clínica: um ensaio de } \\
\text { articulação focalizando o desemprego }\end{array}$ & 2004 & Estudos de Psicologia (Natal) & categoria teórica \\
\hline $\begin{array}{l}\text { Vivendo o sofrimento e os desafios no trabalho: expressões } \\
\text { autocríticas de um grupo de enfermeiros-educadores }\end{array}$ & 2004 & $\begin{array}{l}\text { Revista Eletrônica de } \\
\text { Enfermagem }\end{array}$ & categoria teórica \\
\hline $\begin{array}{l}\text { Paradoxos organizacionais, gestão de pessoas e tecnologia na } \\
\text { Souza Cruz }\end{array}$ & 2004 & RAE-Eletrônica & categoria teórica \\
\hline $\begin{array}{l}\text { A psicologia na transição paradigmática: um estudo sobre o } \\
\text { trabalho na economia solidária }\end{array}$ & 2004 & Doutorado em Psicologia & categoria teórica \\
\hline $\begin{array}{l}\text { Contribuições da ergonomia à saúde do músico: } \\
\text { considerações sobre a dimensão física do fazer musical }\end{array}$ & 2005 & Música Hodie & categoria teórica \\
\hline Especialidades médicas: estudo psicossocial & 2005 & Psicologia Reflexão e Crítica & categoria teórica \\
\hline $\begin{array}{l}\text { Desvelando fatores que afetam a satisfação e a insatisfação no } \\
\text { trabalho de uma equipe de enfermagem }\end{array}$ & 2005 & Mestrado em Enfermagem & categoria teórica \\
\hline $\begin{array}{l}\text { A gestão do medo: o mal como instrumento de gestão na } \\
\text { ótica da psicodinâmica do trabalho }\end{array}$ & 2005 & Revista Gestão e Planejamento & categoria teórica \\
\hline $\begin{array}{l}\text { Qualidade total e o sindicalismo moderado produtivo nos } \\
\text { metalúrgicos da grande Curitiba }\end{array}$ & 2005 & Mestrado em Sociologia & categoria teórica \\
\hline $\begin{array}{l}\text { Percepção de riscos no trabalho rural em uma região agrícola } \\
\text { do Estado do Rio de Janeiro, Brasil: agrotóxicos, saúde e } \\
\text { ambiente }\end{array}$ & 2005 & Cadernos de Saúde Pública & categoria teórica \\
\hline $\begin{array}{l}\text { Estudo etnográfico das implicações das novas tecnologias na } \\
\text { construção da subjetividade dos trabalhadores da UTI }\end{array}$ & 2005 & Psicologìa para América Latina & categoria teórica \\
\hline $\begin{array}{l}\text { A dinâmica satisfação-sofrimento e a qualidade de vida no } \\
\text { trabalho de uma equipe de saúde no atendimento à criança } \\
\text { queimada }\end{array}$ & 2005 & $\begin{array}{l}\text { Doutorado em Engenharia de } \\
\text { Produção (Ergonomia) }\end{array}$ & categoria teórica \\
\hline Afeto no trabalho: o que se discute na literatura nacional & 2005 & Psicologìa para América Latina & categoria teórica \\
\hline $\begin{array}{l}\text { Trabalhador contemporâneo e patologias por hiper- } \\
\text { solicitação }\end{array}$ & 2005 & Psicologia Reflexão e Crítica & categoria teórica \\
\hline
\end{tabular}




\begin{tabular}{|c|c|c|c|}
\hline $\begin{array}{l}\text { O trabalho da enfermagem em unidades críticas e sua } \\
\text { repercussão sobre a saúde dos trabalhadores }\end{array}$ & 2006 & $\begin{array}{l}\text { Escola Anna Nery Revista de } \\
\text { Enfermagem }\end{array}$ & categoria teórica \\
\hline $\begin{array}{l}\text { O sofrimento psíquico em trabalhadores de UTI interferindo } \\
\text { no seu modo de viver a enfermagem }\end{array}$ & 2006 & Revista de Enfermagem UERJ & categoria teórica \\
\hline $\begin{array}{l}\text { Controle por resultados no local de trabalho: dissonâncias } \\
\text { entre o prescrito e o real }\end{array}$ & 2006 & RAE-Eletrônica & categoria teórica \\
\hline $\begin{array}{l}\text { Prazer e sofrimento no trabalho dos líderes religiosos numa } \\
\text { organização protestante neo-pentecostal e noutra tradicional }\end{array}$ & 2006 & Psico-USF & categoria teórica \\
\hline Sofrimento psíquico nas relações de trabalho & 2006 & PSIC & categoria teórica \\
\hline $\begin{array}{l}\text { Adversidades no trabalho: a condição de ser trabalhador no } \\
\text { sistema de produção flexível na indústria automobilística } \\
\text { brasileira }\end{array}$ & 2006 & $\begin{array}{l}\text { Doutorado em Ciências } \\
\text { Humanas }\end{array}$ & categoria teórica \\
\hline $\begin{array}{l}\text { Trabalho policial e saúde mental: uma pesquisa junto aos } \\
\text { capitães da Polícia Militar }\end{array}$ & 2006 & Psicologia Reflexão e Crítica & categoria teórica \\
\hline $\begin{array}{l}\text { Saúde mental e economia solidária: análise das relações de } \\
\text { trabalho em uma cooperativa de confecção de Porto Alegre }\end{array}$ & 2006 & Psicologia \& Sociedade & categoria teórica \\
\hline $\begin{array}{l}\text { O trabalho na rua e a exposição à violência no trabalho: um } \\
\text { estudo com agentes de trânsito }\end{array}$ & 2007 & Interface & $\begin{array}{c}\text { categoria teórico- } \\
\text { metodológica }\end{array}$ \\
\hline $\begin{array}{l}\text { Situações de assédio moral a trabalhadores anistiados } \\
\text { políticos de uma empresa pública }\end{array}$ & 2006 & Psicologia em Revista & categoria teórica \\
\hline Bombeiros: um olhar sobre a qualidade de vida no trabalho & 2007 & Psicologia Ciência e Profissão & categoria teórica \\
\hline O trabalho e seus sentidos & 2007 & Psicologia \& Sociedade & categoria teórica \\
\hline $\begin{array}{l}\text { Centro de Atenção Psicossocial (CAPS): saúde mental do } \\
\text { trabalhador }\end{array}$ & 2007 & $\begin{array}{l}\text { Online Brazilian Journal of } \\
\text { Nursing }\end{array}$ & categoria teórica \\
\hline $\begin{array}{l}\text { Prazer e sofrimento de psicólogos no trabalho em empresas } \\
\text { privadas }\end{array}$ & 2007 & Psicologia Ciência e Profissão & categoria teórica \\
\hline $\begin{array}{l}\text { A saúde e os processos de trabalho no capitalismo: reflexões } \\
\text { na interface da psicodinâmica e da sociologia do trabalho }\end{array}$ & 2007 & Psicologia \& Sociedade & categoria teórica \\
\hline $\begin{array}{l}\text { Trabalho, saúde mental e subjetividade em uma guarda } \\
\text { municipal: estudo em psicodinâmica do trabalho }\end{array}$ & 2008 & $\begin{array}{l}\text { Cadernos de Psicologia Social } \\
\text { do Trabalho }\end{array}$ & categoria teórica \\
\hline $\begin{array}{l}\text { Manda quem pode, obedece quem tem juízo: prazer e } \\
\text { sofrimento psíquico em cargos de gerência }\end{array}$ & 2008 & $\begin{array}{l}\text { Cadernos de Psicologia Social } \\
\text { do Trabalho }\end{array}$ & categoria teórica \\
\hline Cuidadores: seus amores e suas dores & 2008 & Psicologia \& Sociedade & categoria teórica \\
\hline $\begin{array}{l}\text { A psicodinâmica do reconhecimento no trabalho de } \\
\text { enfermagem }\end{array}$ & 2009 & Psico PUCRS & $\begin{array}{c}\text { categoria teórico- } \\
\text { metodológica }\end{array}$ \\
\hline $\begin{array}{l}\text { Experiência em clínica do trabalho com bancários adoecidos } \\
\text { por LER/ DORT }\end{array}$ & 2009 & Psicologia Ciência e Profissão & $\begin{array}{l}\text { categoria teórico- } \\
\text { metodológica }\end{array}$ \\
\hline
\end{tabular}

Podemos observar que as temáticas estudadas foram as mais variadas, o que demonstra que as categorias desenvolvidas pela psicodinâmica do trabalho acabaram sendo utilizadas por disciplinas muito diferentes e que, provavelmente, vieram preencher lacunas nas discussões dessas áreas. Os artigos ficaram distribuídos, tendo em vista a área temática do periódico, de acordo com o Quadro 2:

\section{Quadro 2: Distribuição dos artigos, dissertações e teses por área temática}

\begin{tabular}{|l|c|}
\hline \multicolumn{1}{|c|}{ Área temática } & Número \\
\hline Psicologia & 36 \\
\hline Saúde coletiva & 13 \\
\hline Engenharia de produção (ergonomia) & 12 \\
\hline Enfermagem & 6 \\
\hline Administração & 5 \\
\hline Outros & 7 \\
\hline
\end{tabular}


Os trabalhos da área da psicologia foram os que mais utilizaram a psicodinâmica do trabalho e foi entre eles que encontramos os únicos estudos que utilizaram sua abordagem teórico-metodológica. Nos artigos publicados encontramos uma grande maioria de relatos de pesquisa e apenas alguns de reflexão teórica. Porém, em apenas cinco deles foi possível identificar o uso da metodologia, isto é, o segmento dos passos propostos originalmente pelo método.

Assim, com base nesses estudos identificados, pode-se considerar que a psicodinâmica do trabalho tem sido utilizada no Brasil em duas perspectivas: 1) como categoria teóricometodológica e 2) como categoria teórica.

A perspectiva desses estudos não pretende fragmentar a abordagem e o campo de estudo, criando "escolas" diferenciadas, mas agregar o que vem sendo produzido, com diferentes delineamentos e formatos, visando ampliar e fortalecer o conhecimento. Nesse sentido, defende-se uma única psicodinâmica do trabalho, que, fundamentalmente, é uma teoria crítica do trabalho e uma clínica. O diálogo e as interfaces são importantes para fortalecer sua identidade e consolidar seus pressupostos vinculados à ética e ao real do trabalho, ou seja, ao trabalho vivo, humano, do sujeito. Para tanto, seu uso deve ser pautado na análise das contradições e na dinâmica que envolve as relações intersubjetivas: o sujeito, o trabalho, o sofrimento, a patologia e a normalidade. Principalmente, vale reforçar que esse uso deve ser pautado nas suas bases epistemológicas: a psicanálise e a sociologia crítica, tanto para o debate teórico, como para interpretar os dados originados das investigações empíricas.

Define-se como categoria teórico-metodológica, o uso da teoria e do método baseados no que foi originalmente proposto por Dejours $(1986,2004)$, que pressupõe a indissociabilidade entre a pesquisa e ação. Esse fundamento encontra-se na base da clínica do trabalho, que, ao mesmo tempo, é teoria e método, uma vez que, para revelar o sofrimento por meio da falaescuta, estão implicadas as interpretações conceituais e a ação pela fala.

Os estudos realizados nessa perspectiva têm como preocupação central a mobilização subjetiva dos trabalhadores, por meio do processo de elaboração, perlaboração e ressignificação do sofrimento no trabalho, revelando e reorganizando o sistema de medições frente a esse sofrer. Essa ação dá-se pela palavra, que pode transformar-se em ato, ou seja, provocar a mobilização do fazer na busca de transformação da organização do trabalho, produzindo uma mobilização que também é sociopolítica. Utilizar a psicodinâmica do trabalho como teoria e método não significa a simples reprodução de passos técnicos, mas, sim, a aplicação dos seus pressupostos e a compreensão dos efeitos que a escuta do sofrimento produz nos processos de subjetivação dos trabalhadores e na sua saúde mental. Também implica o engajamento subjetivo, político e ético do pesquisador. A subjetividade, enquanto construção sócio-psíquica na relação com os outros, é o instrumento principal desta perspectiva, que busca emancipar o sujeito por meio da análise psicodinâmica do trabalho. Nesse sentido, identifica-se que alguns estudos, que se propõe a usar a clínica do trabalho, não seguem a risca, tecnicamente, todos os passos do método original, mas mantém-se fiel aos pressupostos, realizando adaptações coerentes e que fortalecem o campo da clínica do trabalho no Brasil.

A categoria teórica tão fundamental quanto a teórico-metodológica, está centrada em discussões teóricas e no uso dos conceitos para delinear pesquisas empíricas, interpretar dados e estabelecer diálogos com outras abordagens. Nesta categoria, classificamos estudos que utilizam o referencial teórico da psicodinâmica do trabalho na construção de artigos teóricos e na pesquisa com outros métodos científicos de coleta e de análise de dados, tanto qualitativos, como quantitativos. Encontra-se nesta categoria a maioria dos estudos, demonstrando o status que a psicodinâmica do trabalho vem assumindo como abordagem teórica, a despeito do método utilizado não ser a clínica do trabalho. 


\section{Como categoria teórico-metodológica}

Alguns pesquisadores têm buscado, nos últimos anos, reproduzir e adaptar o método da clínica do trabalho para as realidades de trabalho brasileiras estudadas, utilizando-o em consonância com o que é proposto originalmente (não apenas como categoria conceitual) e seguindo todas as etapas da investigação. Esses autores entendem que, para o uso da psicodinâmica do trabalho, deve haver uma indissociabilidade entre a teoria e o método. Para eles, alguns conceitos como, por exemplo, sofrimento psíquico no trabalho, só podem ser desvendados a partir de uma utilização estrita do método proposto, com o seguimento de todas suas etapas (pré-pesquisa, pesquisa, devolução e validação dos resultados etc.), aí incluídos os grupos de discussão com trabalhadores (dentro dos moldes propostos pelo método) e a identificação dos mecanismos de defesa construídos por esses trabalhadores, individual ou coletivamente.

Um dos primeiros estudos que aplica o método proposto por Dejours (1986) foi desenvolvido no Brasil por Mendes e Abrahão (1996). Teve por objetivo, investigar o processo de construção da intersubjetividade nas situações de trabalho a partir da análise da relação dinâmica entre a organização do trabalho e o prazer-sofrimento no trabalho de engenheiros eletrônicos. Para tal, foram realizadas dez sessões coletivas, seguindo todos os passos referentes à construção da demanda, pré-análise, pesquisa propriamente dita, restituição e validação com outros pesquisadores. A análise baseou-se na interpretação das falas realizadas pelo coletivo de trabalhadores e pelo coletivo de pesquisa. Os resultados demonstraram o sofrimento decorrente da divisão fragmentada das tarefas e a falta de conteúdo significativo dessas tarefas. $\mathrm{O}$ sofrimento também se relaciona com o surgimento de dificuldades nas relações entre pares e a hierarquia, no nível afetivo, político e social. Essa situação leva à utilização de estratégias defensivas e à imobilização para o engajamento em processos de transformação do trabalho. As vivências de prazer são observadas quando o discurso reflete o contexto em que a organização do trabalho é flexível e os participantes podem utilizar sua criatividade e sentirem-se úteis, produtivos e valorizados.

Essa pesquisa atendeu aos pressupostos do método (Dejours, 1994). Foi composta de três etapas. A primeira, a pré-pesquisa, que se caracteriza pela análise da demanda. A segunda, a pesquisa propriamente dita, ou seja, o momento em que são discutidas coletivamente relações entre organização do trabalho e vivências de prazer e de sofrimento. E a terceira, a validação dos resultados.

Segundo os autores, em consonância com o método da psicodinâmica do trabalho, os trabalhadores em grupo foram capazes de reconstruir a lógica das pressões de trabalho que os faziam sofrer e, também, de fazer aparecer estratégias defensivas coletivamente construídas para lutar contra os efeitos desestabilizadores e patogênicos do trabalho.

A pesquisa também contemplou o coletivo de enquete e o coletivo de controle. A discussão das vivências de prazer-sofrimento provenientes da dinâmica das situações de trabalho foram construídas ao longo das sessões. A análise e as interpretações das situações de trabalho oferecidas pelos pesquisadores e pelos trabalhadores asseguraram a validade do material coletado: o grupo de pesquisadores confrontou permanentemente o conteúdo das sessões entre eles e com o próprio grupo de trabalhadores no momento da realização da pesquisa.

Desse modo, como afirma Dejours (1994), a pesquisa nessa abordagem é um processo de interação, no qual os trabalhadores analisam suas vivências e os pesquisadores propõem hipóteses a serem discutidas. A validação ocorre nesse mesmo contexto, sendo relativa à interpretação dos fatos, e não aos fatos em si, com o objetivo de demonstrar as contradições da relação sofrimento e organização do trabalho. 
Outro estudo que ilustra essa perspectiva, é a pesquisa de Lancman, Sznelwar, Uchida e Tuacek (2007) sobre o trabalho dos agentes de trânsito de São Paulo. Esses autores afirmam que:

\begin{abstract}
A pesquisa baseou-se na psicodinâmica do trabalho, um método circunscrito no âmbito da pesquisa-ação, em que a investigação pressupõe uma ação transformadora na situação estudada. Neste caso, a ação esperada não é somente mudanças na situação pesquisada, mas, sobretudo, no engajamento do coletivo dos trabalhadores como co-responsáveis pela ação em si. Este método busca constituir coletivos de expressão compostos, de um lado, por grupos com trabalhadores envolvidos diretamente na situação estudada e, de outro, por pesquisadores que coordenam e participam dos grupos e que estão, ao mesmo, tempo vinculados a um grupo mais amplo que trabalha simultaneamente como coletivo de controle (p. 85).
\end{abstract}

O método não foi uma mera observação ou coleta de dados, pois os aspectos subjetivos do trabalho foram compreendidos a partir de uma discussão realizada em um espaço aberto à deliberação:

As interpretações e os sentidos para os fatos apresentados não são construídos, de fora, pelos pesquisadores, mas são frutos do sentido que aquela situação tem para os próprios indivíduos. Esse processo, denominado por Dejours de perlaboração coletiva, só é possível pela reapropriação e vontade de emancipação dos trabalhadores participantes (Lancman et al., 2007, p. 85).

Nesse estudo foram seguidas estritamente todas as etapas preconizadas na metodologia: pré-pesquisa, reconfiguração da demanda, apresentação do projeto aos trabalhadores (para que estes conhecessem os objetivos da pesquisa-ação e pudessem escolher se gostariam de participar dos grupos), restituição e validação. Após a última etapa, o relatório final foi apresentado ao conjunto dos trabalhadores que não participaram diretamente dos grupos e à instituição.

Ainda segundo os autores:

Foram constituídos dois grupos de reflexão: o primeiro, composto por seis trabalhadores, onde adotaram, como critério de inclusão, agentes que permaneciam na fiscalização do estacionamento rotativo; o segundo composto por oito trabalhadores que haviam sido transferidos da atividade de fiscalização da Zona Azul para a operação de tráfego. Os dois grupos ocorreram durante o horário de trabalho, ao longo de seis sessões de uma hora e meia de duração, com frequência semanal. Ao final, após um período de elaboração dos relatórios, os mesmos foram validados com os participantes dos grupos. Somente após essas validações foi composto um relatório apresentado ao conjunto dos trabalhadores e debatido com diferentes níveis hierárquicos da empresa (Lancman et al., 2007, p. 86).

Os resultados indicaram que o convívio com a violência no exercício do trabalho produziu nos trabalhadores, de um lado, um forte impacto na saúde mental e, de outro, o desenvolvimento de estratégias e uma inteligência relacionada ao trabalho para poderem continuar a trabalhar.

Em um estudo com a Guarda Municipal de Porto Alegre, no qual a metodologia também foi utilizada de forma estrita, buscou-se compreender quais as implicações da reestruturação daquela guarda na dinâmica saúde-adoecimento mental dos trabalhadores. Foi constatado que:

O espaço de fala e escuta criado pelos encontros em grupo pode se constituir em importante aspecto para a reelaboração das estratégias defensivas e reflexão sobre a organização do trabalho. Nesse sentido foi construída, em parceria com os guardas 
municipais, uma proposta de continuidade dos encontros em grupo, que se encontra em andamento, visando um espaço de intervenção (Baierle \& Merlo, 2008).

Nessa pesquisa, que se prolongou por dois anos, foi possível observar a eficácia da psicodinâmica do trabalho como método investigativo, mas, também, como instrumento de intervenção. Após um primeiro período de coleta de dados de seis meses e um afastamento de quatro meses, retornou-se ao campo investigado e, através da reestruturação dos grupos de discussão, foi possível constatar que várias modificações no trabalho dos guardas municipais haviam sido implementadas por eles mesmos, buscando reduzir alguns aspectos nocivos à saúde mental. Na medida em que a proposta foi executada como uma pesquisa-intervenção, nem sempre é possível delimitar as influências de um primeiro momento de pesquisa e um outro de intervenção propriamente dita.

Por fim, destaca-se um estudo de Vital-Júnior et al. (2009), que apresenta algumas peculiaridades em relação à clínica do trabalho, abrindo a possibilidade de ampliar sua aplicação na intervenção junto a trabalhadores adoecidos. Nesse sentido, o estudo realizou uma intervenção em clínica do trabalho com grupos de bancários acometidos de LER/DORT. Foram formados dois grupos, cada um com seis trabalhadores afastados do trabalho, realizando-se dez sessões com cada grupo. Os resultados evidenciaram que mecanismos organizacionais, como as promessas simbólicas, estimulam a sobrecarga do corpo para a mediação do medo e da ansiedade, favorecendo o processo de adoecimento. A experiência mostrou-se positiva para os participantes ressignificarem seu processo de adoecimento por meio de um espaço de discussão no qual as vivências de prazer-sofrimento e os modos de mediação foram compartilhados.

Nestes dois últimos estudos, a pesquisa e a ação são consideradas partes da intervenção. A fala mobiliza o trabalhador para ressignificar sua relação com o trabalho e fazer as transformações nas estratégias para dar conta do real, aproximando-as o mais possível das condições de saúde.

\section{Como categoria teórica}

Trata-se da utilização das categorias teóricas da psicodinâmica do trabalho para tentar compreender as realidades de trabalho, buscando uma superação dos limites impostos por outras abordagens ou outros métodos existentes. Nessa situação encontram-se a grande maioria dos estudos produzidos por pesquisadores da área de saúde mental e mesmo de fora dela, tendose como base o levantamento realizado. Esses estudos versam sobre objetos e temáticas as mais diversas e que necessitaram buscar no referencial teórico da psicodinâmica do trabalho um instrumento que permitisse uma interpretação mais aprofundada dos resultados encontrados. Nesta categoria, o método da clínica do trabalho não tem sido utilizado ou tem sofrido adaptações.

Dos estudos analisados, identificam-se alguns que utilizam a psicodinâmica como teoria combinada a multi-métodos, como por exemplo: Valores organizacionais e prazer-sofrimento no trabalho e "Só de pensar em vir trabalhar, já fico de mau humor": atividade de atendimento ao público e prazer-sofrimento no trabalho.

Essa tendência está claramente apresentada e analisada no livro Psicodinâmica do trabalho: teoria, método e pesquisa, organizado por Mendes (2007). É importante ressaltar que essa combinação pode significar a amplificação ou a restrição na apreensão do objeto. $O$ delineamento do objeto de pesquisa é que define o método. Em alguns dos estudos reunidos por Mendes (2007), o método estrito sofreu adaptações ou foi combinado com outras estratégias de coleta e análise de dados. É importante destacar que, quanto mais essas técnicas se aproximam do método estrito, mais é possível a apreensão do objeto mesmo da psicodinâmica do trabalho. 
Quanto menos ocorre essa aproximação, mais os estudos são descritivos, com a identificação de indicadores, não permitindo a interpretação das relações intersubjetivas.

Isso significa que um questionário ou uma análise documental vão permitir a descrição dos indicadores do sofrimento, mas não a compreensão das vivências e das dinâmicas. Esse tipo de delineamento metodológico limita as possibilidades de mobilização do trabalhador, aquela possível na fala enquanto ato, mas certamente não invalida a contribuição ao avanço do campo. Esse tipo de pesquisa pode identificar o perfil dos trabalhadores brasileiros em termos de riscos de adoecimento - ao investigarem os indicadores de sofrimento em termos de presença, frequência e intensidade -, podendo, assim, subsidiar as políticas e ações de prevenção aos riscos à saúde.

Essa combinação tem ampliado significativamente a produção científica em psicodinâmica do trabalho. Apesar de ser uma disciplina nova, as pesquisas no Brasil produziram estudos empíricos com uma ampla gama de categorias profissionais, desvelando aspectos invisíveis do trabalho, descrevendo particularidades da organização do trabalho, vivências de prazer-sofrimento, estratégias de mediação do sofrimento e identificando riscos e danos à saúde mental dos trabalhadores.

Nesses estudos que lançam mão das categorias teóricas da psicodinâmica do trabalho, as entrevistas aparecem como a principal ferramenta de coleta de dados. Elas podem ser tanto individuais, quanto coletivas, estruturadas ou semi-estruturadas. Vários estudos também empregaram questionários, escalas, análise documental e observação sistemática. A análise dos dados é predominantemente qualitativa, apoiada no arcabouço teórico da psicodinâmica do trabalho. Utilizam-se como técnicas a análise de conteúdo (Bardin, 1970), a análise de núcleos de sentido (Mendes, 2007) e a análise clínica do trabalho (Rossi, 2008).

É comum a todos esses estudos a afiliação aos pressupostos da psicodinâmica do trabalho como teoria para fundamentar o método usado. Para Mendes (2007), é "objeto da psicodinâmica do trabalho o estudo das relações dinâmicas entre organização do trabalho e processos de subjetivação" (p. 29). O acesso a essas relações dinâmicas dá-se pela palavra. No caso do trabalho prescrito, a palavra registrada. No caso do trabalho real, a palavra relatada pelo trabalhador. É na palavra expressa que se possibilita ressignificar o sofrimento, onde ele pode ser reconhecido e discutido, consequentemente, fortalecendo as relações de camaradagem, solidariedade, cooperação, empatia, ou seja, relações fundamentais na constituição do coletivo de trabalho.

Essa palavra não existe por si só, ela precisa ser expressa. "A saída para essa problemática da transformação do sofrimento é o espaço público da fala, constituído pela cooperação, que reflete o trabalho vivo, as dinâmicas intersubjetivas e a política. Implica um espaço de opiniões, eventualmente contraditórias, que podem ser livremente formuladas e publicamente declaradas" (Mendes, 2008, p. 24). Nesse sentido, as entrevistas proporcionam um espaço para elaboração e expressão do trabalho. Pensar e falar sobre o trabalho é mobilizar o sujeito para agir sobre o trabalho.

Essa fala gera resistências. Escutar é um risco (Dejours, 2004, 2007). Um risco de dar vazão a um conteúdo inconsciente, de reconhecer o sofrimento e modificar a organização do trabalho. Um risco de combater a dinâmica da alienação imposta pela organização do trabalho. Nesse risco, faz-se necessário tomar cuidados éticos para tentar evitar consequências desagradáveis desencadeadas em função da pesquisa. A não identificação dos sujeitos ou da instituição é uma estratégia de produzir conhecimento sem que os pesquisados paguem um preço incompatível com o esforço da produção do conhecimento.

Qualquer que seja a perspectiva do uso da psicodinâmica do trabalho, é fundamental o olhar clínico. Esse olhar é o diferencial desta abordagem, seja qual for a combinação metodológica. Esse olhar é que vai dar a sustentação, ao lado do referencial teórico, à pesquisa 
e à prática profissional em psicodinâmica do trabalho. É um olhar clínico que busca as discrepâncias entre o trabalho prescrito e o trabalho real. Discrepância que implica em utilização das estratégias de mobilização coletiva e das estratégias individuais pelos trabalhadores. Identificar e analisar essas estratégias e suas relações com a organização do trabalho é a grande contribuição que se pretende com a pesquisa em psicodinâmica do trabalho. O método é o caminho que regula o grau de profundidade com o qual o pesquisador consegue apreender esse objeto.

Como sabemos que existem outros estudos publicados, além daqueles analisados neste artigo, não é possível estabelecer parâmetros para produzir uma classificação mais conclusiva das perspectivas da psicodinâmica do trabalho no Brasil, para delinear suas similaridades e diferenças e, especialmente, para organizar os estudos em eixos específicos. Por essa razão, este artigo não se propõe a ser conclusivo, mas tem a intenção de propor uma discussão sobre o uso do método, a partir de uma primeira abordagem, com cunho exploratório.

\section{Comentários finais}

As referências citadas no Quadro 1 são, certamente, apenas uma parcela do que poderíamos encontrar na literatura científica brasileira atual. Quaisquer que sejam as perspectivas assumidas pelos estudos em psicodinâmica do trabalho, eles oferecem contribuições valiosas para o crescimento do campo. Isso apenas demonstra a força das conceituações produzidas pela abordagem desde a criação do método e que têm sido utilizadas de forma ampla para explicar as consequências de realidades e organizações de trabalho muito diversas sobre a saúde psíquica dos indivíduos.

Múltiplas abordagens e métodos foram criados para estudar as relações entre trabalho e saúde mental e não é intenção deste texto descrevê-las e analisá-las em sua totalidade. É importante, no entanto, lembrar sempre que as realidades podem ser apreendidas de várias maneiras e que nenhum método sozinho é capaz de dar conta de todos os seus aspectos. Entendemos que as diversas tendências utilizadas na abordagem analisada devem ser vistas, antes de mais nada, como complementares e não como excludentes. Apesar dos avanços da discussão ocorridos, principalmente nos últimos vinte anos, ainda existem importantes lacunas na compreensão das relações entre trabalho e saúde mental, que limitam e criam impasses ainda não resolvidos para, por exemplo, a atenção à saúde nos serviços que atendem os trabalhadores. Basta lembrar as dificuldades para o estabelecimento do nexo causal entre trabalho e saúde mental, que é uma questão ainda não devidamente resolvida e que limita a atividade dos profissionais de saúde que atuam nos centros de referência em saúde do trabalhador, nos ambulatórios de doenças do trabalho dos hospitais universitários e nas unidades básicas de saúde. Esses campos e práticas profissionais ainda precisam ser amplamente investigados, fortalecendo, assim, a tendência de usar a psicodinâmica do trabalho enquanto uma clínica do trabalho aplicada à gestão da organização do trabalho e às ações e políticas públicas de prevenção de doenças mentais ocupacionais.

Acredita-se que todos os métodos devem ser vistos como instrumentos de trabalho para a pesquisa em permanente construção - e por isso dinâmicos -, que precisam ser adequados às realidades nas quais são utilizadas e para seus horizontes de utilização, podem e devem ser muito ampliados. Com a psicodinâmica do trabalho não ocorre diferentemente. As várias experiências realizadas até hoje por pesquisadores brasileiros utilizando esse método, indicam que o método permite, não apenas produzir uma investigação e, portanto, novos conhecimentos, mas, também, revela-se um instrumento para intervenção, prevenção e transformação de processos de trabalho agressivos à saúde psíquica. Nesse sentido, buscar seu 
uso como categoria teórico-metodológica é o cenário ideal que, muitas vezes, não corresponde ao real do campo de pesquisa, mas que precisa ser buscado, como possibilidade de assegurar a perspectiva transformadora desta abordagem.

\section{Referências}

Vital-Júnior, A, Mendes, A. M. \& Araújo, L. K. R. (2009). Experiência em clínica do trabalho com bancários adoecidos por LER/DORT. Psicologia Ciência e Profissão, 29 (3), 614-625.

Abrahão, J. I. \& Torres, C. C. (2004). Entre a organização do trabalho e o sofrimento: o papel de mediação da atividade. Revista Produção, 14 (3), 67-76.

Acosta, J. M. de A. (2004). Avaliação do sistema de gestão de riscos de acidentes com instrumentos pérfuro-cortantes na atividade de limpeza de hospitais públicos através da análise ergonômica do trabalho. Dissertação de Mestrado, Programa de Pós-Graduação em Engenharia de Produção, Universidade Federal de Minas Gerais, Belo Horizonte.

Almeida, L. L. \& Merlo, A. R. C. (2008). Manda quem pode, obedece quem tem juízo: prazer e sofrimento psíquico em cargos de gerência. Cadernos de Psicologia Social do Trabalho, 11 (2), 139-157.

Ansaloni, J. A. \& Ésther, A. B. (1999). Relações de trabalho e inovação tecnológica na gerência de sistemas de uma organização produtora de jornais. Revista de Administração Contemporânea, 3 (2), 119-135.

Baierle, T. C. \& Merlo, A. R. C. (2008). Trabalho, saúde mental e subjetividade em uma guarda municipal: estudo em psicodinâmica do trabalho. Cadernos de Psicologia Social do Trabalho, 11 (1), 69-81.

Bardin, L. (1977). Análise de conteúdo. Lisboa: Edições 70.

Barbarini, N. \& Merlo, A. R. C. (2002). Reestruturação produtiva no setor bancário brasileiro e sofrimento dos caixas executivos. Psicologia Eु Sociedade, 14 (1), 103-122.

Barcellos, J. A. P. (1999). As condições e a organização de trabalho dos policiais militares que executam o policiamento ostensivo: um estudo de caso na Brigada Militar em Porto Alegre/RS. Dissertação de Mestrado, Programa de Pós-Graduação em Administração, Universidade Federal do Rio Grande do Sul, Porto Alegre.

Barfknecht, K. S., Merlo, A. R. C. \& Nardi, H. C. (2006). Saúde mental e economia solidária: análise das relações de trabalho em uma cooperativa de confecção de Porto Alegre. Psicologia E Sociedade, 18 (2), 54-61.

Barros, P. C. da R. \& Mendes, A. M. B. (2003). Sofrimento psíquico no trabalho e estratégias defensivas dos operários terceirizados da construção civil. Psico-USF, 8 (1), 63-70.

Beck, C. L. C., Gonzales, R. M. B., Stekel, L. M. C. \& Donaduzzi, J. C. (2006). O trabalho da enfermagem em unidades críticas e sua repercussão sobre a saúde dos trabalhadores. Escola Anna Nery Revista de Enfermagem, 10 (2), 221-227.

Brant, L. C. \& Minayo-Gomez, C. (2004). A transformação do sofrimento em adoecimento: do nascimento da clínica à psicodinâmica do trabalho. Ciência $\mathscr{E}$ Saúde Coletiva, 9 (1), 213-223.

Braz, M. M. (2001). Aprendendo com o câncer de mama: percepções e emoções de pacientes e profissionais de fisioterapia. Dissertação de Mestrado, Programa de Pós-Graduação em Engenharia de Produção, Universidade Federal de Santa Catarina, Florianópolis.

Cimbalista, S. N. (2006). Adversidades no trabalho: a condição de ser trabalhador no sistema de produção flexível na indústria automobilística brasileira. Tese de Doutorado, Programa de Pós-Graduação Interdisciplinar em Ciências Humanas, Universidade Federal de Santa Catarina, Florianópolis.

Costa, C. R. (2000). Alunos problemas - professores despreparados. Dissertação de Mestrado, Programa de Pós-Graduação em Engenharia de Produção, Universidade Federal de Santa Catarina, Florianópolis.

Costa, C. P. (2005). Contribuições da ergonomia à saúde do músico: considerações sobre a dimensão física do fazer musical. Música Hodie, 5 (2), 53-63.

Cunha, E. G. \& Mazzilli, C. (2005). A gestão do medo: o mal como instrumento de gestão na ótica da psicodinâmica do trabalho. Gestão $\mathcal{E}$ Planejamento, 6 (11), 32-46.

D'Acri, V. (2003). Trabalho e saúde na indústria têxtil de amianto. São Paulo em Perspectiva, 17 (2), 13-22.

Dejours, C. (1987a). A loucura do trabalho: estudo de psicopatologia do trabalho. São Paulo: Oboré. 
Dejours, C. (1987b). Aspects en psychopathologie du travail. In C. Lévy-Leboyer \& J. C. Sperandio (Orgs.), Traité de psychologie du travail (pp. 729-747). Paris: PUF.

Dejours, C. (1992). Intelligence ouvrière et organisation du travail (a propôs du modele japonais de production). In H. Hirata (Org.), Autour du "uodèle" japonais: automatisation, nouvelles formes d'organisation et de relations de travail (pp. 275-303). Paris: Harmattan.

Dejours, C. (2004). A metodologia em psicodinâmica do trabalho. In S. Lancman \& L. Sznelwar (Org.), Christophe Dejours: da psicopatologia à psicodinâmica do trabalho (pp. 105-126). Rio de Janeiro: Fiocruz.

Dejours, C. (2007). Psicodinâmica do trabalho na pós-modernidade. In A. M. Mendes, S. Lima \& E. P. Facas (Orgs.), Diálogos em psicodinâmica do trabalho (pp.13-26). Brasília: Paralelo 15.

Ferreira, M. C. \& Mendes, A. M. (2001). "Só de pensar em vir trabalhar, já fico de mau humor": atividade de atendimento ao público e prazer-sofrimento no trabalho. Estudos de Psicologia (Natal), 6 (1), 93-104.

Ferreira, J. B., Mendes, A. M. \& Calgaro, J. C. C. et al. (2006). Situações de assédio moral a trabalhadores anistiados políticos de uma empresa pública. Psicologia em Revista, 12 (20), 215-233.

Fiore, M. L. M. \& Yazigi, L. (2005). Especialidades médicas: estudo Psicossocial. Psicologia: Reflexão e Crítica, 18 (2), 200-206.

Formighieri, V. J. (2003). Burnout em fisioterapeutas: influência sobre a atividade de trabalho e bem-estar físico e psicológico. Dissertação de Mestrado, Programa de Pós-Graduação em Engenharia de Produção, Universidade Federal de Santa Catarina, Florianópolis.

Gallo, C. M. C. (2005). Desvelando fatores que afetam a satisfação e a insatisfação no trabalho de uma equipe de enfermagem. Dissertação de Mestrado, Programa de Pós-Graduação em Educação, Fundação Universidade Federal de Blumenal, Blumenal.

Ghisleni, A. P. \& Merlo, A. R. C. (2005). Trabalhador contemporâneo e patologias por hipersolicitação. Psicologia: Reflexão e Crítica, 18 (2), 171-176.

Glanzer, C. H., Olschowsky, A. \& Kantorski, L. P. (2007). Centro de Atenção Psicossocial (CAPS): saúde mental do trabalhador. Online Brazilian Journal of Nursing, 6 (3), 1-3.

Glina, D. M. R., Rocha, L. E., Batista, M. L. \& Mendonça, M. G. V. (2001). Saúde mental e trabalho: uma reflexão sobre o nexo com o trabalho e o diagnóstico, com base na prática. Cadernos de Saúde Pública, 17 (3), 607 616.

Gomes, G. C., Lunardi Filho, W. D. \& Erdmann, A. L. (2006). O sofrimento psíquico em trabalhadores de UTI interferindo no seu modo de viver a enfermagem. Revista de Enfermagem UERJ, 14 (1), 93-99.

Gui, R. T. (2002). Prazer e sofrimento no trabalho: representações sociais de profissionais de recursos humanos. Psicologia: Ciência e Profissão, 22 (4), 86-93.

Haddad, M. do C. L. (2000). Qualidade de vida dos profissionais de enfermagem. Revista Espaço para a Saúde, 1 (2), 75-88.

Heloani, J. R. \& Capitão, C. G. (2003). Saúde mental e psicologia do trabalho. São Paulo em Perspectiva, 17(2), 102. 108.

Hopper, K. R. \& Faria, J. H. (2006). Controle por resultados no local de trabalho: dissonâncias entre o prescrito e o real. RAE-Eletrônica, 5 (1).

Jacques, M. da G. C. (2003). Abordagens teórico-metodológicas em saúde/doença mental \& trabalho. Psicologia $\mathfrak{E}$ Sociedade, 15 (1), 97-116.

Jacometti, M., Oliveira, J., Silva, J. T., Dergint, D. E. A. \& Pilatti, L. A. (2004). Gestão do conhecimento como processo de institucionalização da mais-valia relativa. Anais do XXIV Encontro Nacional de Engenharia de Produção, Florianópolis.

Lapo, F. R. \& Bueno, B. O. (2002). O abandono do magistério: vínculos e rupturas com trabalho docente. Psicologia USP, 13 (2), 243-276.

Lancman, S., Sznelwar, L. I., Uchida, S. \& Tuacek, T. A. (2007). O trabalho na rua e a exposição à violência no trabalho: um estudo com agentes de trânsito. Interface - Comunicação, Saúde e Educação, 11 (21), 79-92.

Lancman, S. \& Uchida, S. (2003). Trabalho e subjetividade: o olhar da psicodinâmica do trabalho. Cadernos de Psicologia Social do Trabalho, 6, 79-90.

Lemos, J. C., Cruz, R. M. \& Botomé, S. P. (2002). Sofrimento psíquico e trabalho de profissionais de enfermagem. Estudos de Psicologia (Natal), 7 (2), 407-409. 
Machado, R. R. (2002). A passagem de plantão no contexto do processo de trabalho da enfermagem. Dissertação de Mestrado. Programa de Pós-Graduação em Educação, Universidade Federal de Santa Catarina, Florianópolis.

Machado, A. G. \& Merlo, A. R. C. (2008). Cuidadores: seus amores e suas sores. Psicolo gia Ë Sociedade, 20 (3), 444-452.

Martins, J. C. de O. \& Pinheiro, A. de A. G. (2006).Sofrimento psíquico nas relações de trabalho. PSIC - Revista de Psicologia da Vetor Editora, 7 (1), 79-85.

Minayo-Gomez, C. \& Thedim-Costa, S. M. da F. (2003). Incorporação das ciências sociais na produção de conhecimentos sobre trabalho e saúde. Ciência $\mathcal{G}$ Saúde Coletiva, 8 (1), 125-136.

Mendes, A. M. \& Abrahão, J. I. (1996). A influência da organização do trabalho nas vivências de prazer-sofrimento dos trabalhadores: uma abordagem psicodinâmica. Psicologia Teoria e Pesquisa, 26 (2), 179-184.

Mendes, A. M. \& Tamayo, A. (2001). Valores organizacionais e prazer-sofrimento no trabalho. Psico-USF, 6 (1), 39. 46.

Mendes, A. M. (2002). Algumas contribuições teóricas do referencial psicanalítico para as pesquisas sobre organizações, Estudos de Psicologia (Natal), 7 (número especial), 89-96.

Mendes, A. M. \& Silva, B. R. R. (2006). Prazer e sofrimento no trabalho dos líderes religiosos numa organização protestante neopentecostal e noutra tradicional. Psico-USF, 11 (1), 103-112.

Mendes, A. M. (2007). (Org.). Psicodinâmica do trabalho: teoria, método, pesquisas. São Paulo: Casa do Psicólogo.

Merlo, A. R. C., Jacques, M. da G. C. \& Hoefel, M. da G. L. (2001). Trabalho de grupo com portadores de LER/DORT: relato de experiência. Psicologia: Reflexão e Crítica, 14 (1), 253-258.

Merlo, A. R. C. (2002). Psicodinâmica do trabalho. In M. G. Jacques \& W. Codo (Orgs.), Saúde mental e trabalho: leituras (pp. 130-142). Petrópolis: Vozes.

Merlo, A. R. C. \& Barbarini, N. (2002). Reestruturação produtiva no setor bancário brasileiro e sofrimento dos caixas executivos: um estudo de caso. Psicologia Eु Sociedade, 14 (1), 103-122.

Merlo, A. R. C. et al. (2003). O trabalho entre prazer, sofrimento e adoecimento: a realidade dos portadores de lesões por esforços repetitivos. Psicologia $\mathscr{G}$ Sociedade, 15 (1), 117-136.

Merlo, A. R. C. \& Lapis, N. L. (2007). A saúde e os processos de trabalho no capitalismo: reflexões na interface da psicodinâmica do trabalho e da sociologia do trabalho. Psicologia E Sociedade, 19 (1), 61-68.

Minayo-Gomez, C. \& Thedim-Costa, S. M. F. (1997). A construção do campo da saúde do trabalhador: percurso e dilemas . Cadernos de Saúde Pública, 13 (suplemento 2), 21-32.

Monteiro, J. K., Maus, D., Machado, F. R., Pesenti, C., Bottega, D. \& Carniel, L. B. (2007). Bombeiros: um olhar sobre a qualidade de vida no trabalho. Psicologia Ciência e Profissão, 27 (3), 554-565.

Morin, E., Tonelli, M. J. \& Pliopas, A. L. V. (2007). O trabalho e seus sentidos. Psicologia Eु Sociedade, 19 (número especial), 47-56.

Moulin, M. das G. B., Reis, C. T. \& Wenichi, G. H. (2001). Homens de pedra? Pesquisando o processo de trabalho e saúde na extração e no beneficiamento do mármore - relato de uma experiência. Cadernos de Psicologia Social do Trabalho, 3/4, 47-63.

Palácios, M., Duarte, F. \& Câmara, V. de M. C. (2002). Trabalho e sofrimento psíquico de caixas de agências bancárias na cidade do Rio de Janeiro. Cadernos de Saúde Pública, 18 (3), 843-851.

Penkal, R. J. (2005). Qualidade total e o sindicalismo moderado produtivo nos metalúrgicos da grande Curitiba. Dissertação de Mestrado, Programa de Pós-Graduação em Sociologia, Universidade Federal do Paraná, Curitiba.

Peres, F., Rozemberg, B. \& Lucca, S. R. (2005) Percepção de riscos no trabalho rural em uma região agrícola do Estado do Rio de Janeiro, Brasil: agrotóxicos, saúde e ambiente. Cadernos de Saúde Pública, 21 (6), 1836 1844.

Pinto, L. H. de O. (2001). Comportamento humano no trabalho: educação profissional, subjetividade e falhas operacionais na indústria. Revista da FAEEBA, 10 (16), 85-97.

Ribeiro, F. S. N., Oliveira, S., Reis, M. M., Silva, C. R. S., Menezes, M. A. C., Dias, A. E. X., Moreira, J. C. \& Kuryiama, G. S. (2002). Processo de trabalho e riscos para a saúde dos trabalhadores em uma indústria de cimento. Cadernos de Saúde Pública, 18 (5), 1243-1250.

Rossi, E Z. (2008). Reabilitação e reinserção no trabalho de bancários portadores de LER/DORT: análise psicodinâmica. Tese de Doutorado, Instituto de Psicologia, Universidade de Brasília, Brasília. 
Sampaio, J. dos R. (2002). A “dinâmica de grupos” de Bion e as organizações de trabalho. Psicologia USP, 13 (2), 277-291.

Santos, V. M. V. (2001). Modelo de avaliação de projetos enfoque cognitivo e ergonômico. Tese de Doutorado, Programa de Pós-Graduação em Engenharia de Produção, Universidade Federal de Santa Catarina, Florianópolis.

Sato, L. (2002). Prevenção de agravos à saúde do trabalhador: replanejando o trabalho através das negociações cotidianas. Cadernos de Saúde Pública, 18 (5), 1147-1166.

Sato, L. \& Schmidt, M. L. S. (2004). Psicologia do trabalho e psicologia clínica: um ensaio de articulação focalizando o desemprego. Estudos de Psicologia, 9 (2), 365-371.

Seligmann-Silva, E. (1997). Saúde mental e automação: a propósito de um estudo de caso no setor ferroviário. Cadernos de Saúde Pública, 13 (suplemento 2), 95-109.

Silva, P. C. \& Merlo, A. R. C. (2007). Prazer e sofrimento de psicólogos no trabalho em empresas privadas. Psicologia Ciência e Profissão, 27 (1), 132-147.

Sznelwar, L. \& Uchida, S. (2004). Ser auxiliar de enfermagem: um olhar da psicodinâmica do trabalho. Prod. [online], 14 (3), 87-98.

Souza, K. R., Rozemberg, B., Kelly-Santos, A., Yasuda, N. \& Sharapin, M. (2003). O desenvolvimento compartilhado de impressos como estratégia de educação em saúde junto a trabalhadores de escolas da rede pública do Estado do Rio de Janeiro. Cadernos de Saúde Pública, 19 (2), 495-504.

Stolf, M. C. \& Oliveira, M. R. (2005). Estudo etnográfico das implicações das novas tecnologias na construção da subjetividade dos trabalhadores da UTI. Psicologìa para América Latina, 4.

Tavares, C. R. G. (2000). A Ergonomia e suas contribuições para o processo de ensino-aprendizagem: uma análise das salas de aula do CEFET/RN. Dissertação de Mestrado, Programa de Pós-Graduação em Engenharia de Produção, Universidade Federal de Santa Catarina, Florianópolis.

Traesel, E. S. \& Merlo, A. R. C. (2009). A psicodinâmica do reconhecimento no trabalho de enfermagem. Psico PUCRS, 40 (1), 102-109.

Trevisan, E. M. B. M. (2005). A dinâmica satisfação-sofrimento e a qualidade de vida no trabalho de uma equipe de saúde no atendimento à criança queimada. Dissertação de Mestrado, Programa de Pós-Graduação em Engenharia de Produção, Universidade Federal de Santa Catarina, Florianópolis.

Uchida, S. (1998). Trabalho informatizado e sofrimento psíquico. Psicologia USP, 9 (2), 179-204.

Valle, A. da R. (2005). Afeto no trabalho: o que se discute na literatura nacional. Psicologìa para América Latina, 3.

Vasconcelos, A. S. F. (2000). A saúde sob custódia: um estudo sobre agentes de segurança penitenciária no Rio de Janeiro. Dissertação de Mestrado, Escola Nacional de Saúde Pública, Fundação Oswaldo Cruz, Rio de Janeiro.

Vasconcelos, I., Mascarenhas, A. O. \& Vasconcelos, F. C. (2004). Gestão de pessoas: paradoxos organizacionais, gestão de pessoas e tecnologia na Souza Cruz. RAE-Eletrônica, 3 (2).

Vasconcelos. C. M. da C. B. \& Prado, M. L. (2004). Vivendo o sofrimento e os desafios no trabalho: expressões autocríticas de um grupo de enfermeiros-educadores. Revista Eletrônica de Enfermagem, 6, (1), 47-58.

Velloso, M. P., Santos, E. M. \& Anjos, L. A. (1997). Processo de trabalho e acidentes de trabalho em coletores de lixo domiciliar na cidade do Rio de Janeiro, Brasil. Cadernos de Saúde Pública, 13 (4), 693-700.

Veronese, M. V. (2004). A psicologia na transição paradigmática: um estudo sobre o trabalho na economia solidária. Tese de Doutorado, Programa de Pós-Graduação em Psicologia, Pontifícia Universidade Católica do Rio Grande do Sul, Porto Alegre.

Verthein, M. A. R. \& Minayo-Gomez, C. (2000). A construção do "sujeito-doente" em LER. História, Ciências, Saúde - Manguinhos, 7 (2), 329-347.

\section{Endereço para correspondência}

merlo@ufrgs.br, anamag.mendes@gmail.com 